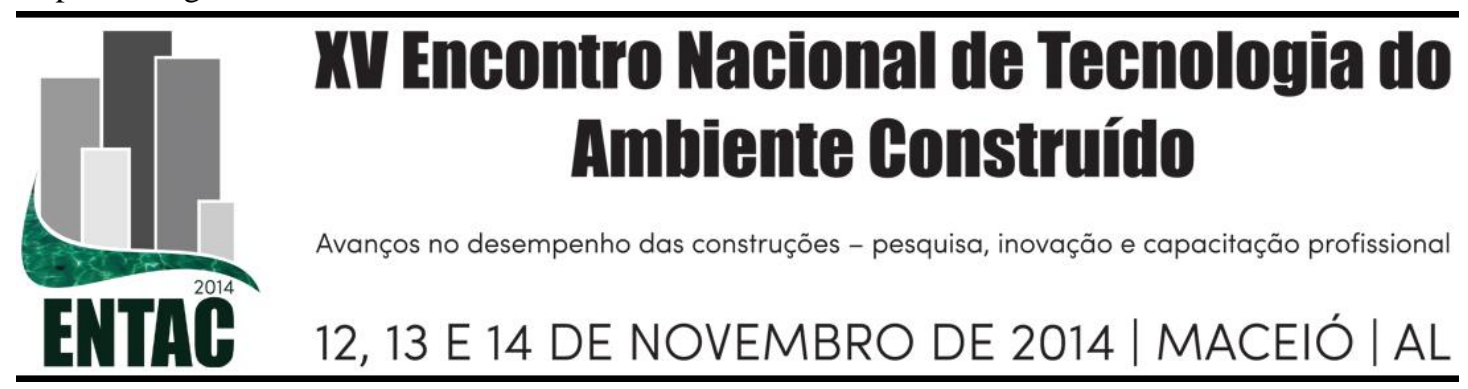

\title{
DESENVOLVIMENTO DE QUESTIONÁRIO PARA LEVANTAMENTO DA PERCEPÇÃO SOBRE ACESSO SOLAR EM CURITIBA
}

\author{
TAMURA, Cíntia A. (1); KRÜGER, Eduardo L. (2)
}

(1) Universidade Tecnológica Federal do Paraná (UTFPR), (41)8870-1002, e-mail: cintiatamura@gmail.com (2) UTFPR, e-mail: ekruger@utfpr.edu.br

\begin{abstract}
RESUMO
A provisão de acesso solar é o requisito elementar para se obter de forma passiva iluminação e aquecimento em interiores. Porém, quando regulamentações urbanísticas são insuficientes ou inexistentes quanto a recomendações para quantidades mínimas diárias e níveis adequados de acesso solar, a geometria resultante das edificações pode ocasionar entre si bloqueio solar, sombreamento, umidade e frio. Soma-se a este fato o desconhecimento e/ou desconsideração por parte de profissionais da área acerca da percepção e preferências relacionadas ao acesso solar dos usuários destas edificações, o que pode resultar em situações em que o conforto ambiental atende a recomendações técnicas, mas não a demandas humanas. O objetivo do estudo foi produzir uma ferramenta validada para o levantamento de dados quantitativos acerca da percepção relacionada ao acesso solar em moradores de 138 unidades habitacionais de Curitiba, capital mais fria do Brasil. Esta pertencente à Zona Bioclimática 1, onde o aproveitamento do potencial de iluminação e aquecimento solar é criticamente necessário. Como referência, utilizou-se um questionário existente em inglês, criado com o intuito de levantar preferências relacionadas a tempo, quantidade, local e propósito do acesso solar, em moradores em conjuntos habitacionais de Hong Kong. O questionário original foi inicialmente traduzido e adaptado por meio da técnica de back translation; a seguir, foi submetido à análise de aparência e conteúdo por cinco especialistas em iluminação natural. Após a adoção das considerações dos mesmos, foi realizado um teste piloto entre 3 e 6 de março de 2014, com a aplicação do questionário a uma amostra selecionada probalisticamente ( $\mathrm{n}=33,24 \%$ da população avaliada). Os dados coletados tiveram seu índice de confiabilidade calculado e atestado pelo índice alfa de Cronbach ( $\alpha=0,838$ ), indicando que o questionário criado é apropriado ao fim que se destina, e pode contribuir em pesquisas sobre a percepção humana relacionada ao acesso solar.
\end{abstract}

Palavras-chave: Validação Questionário, Acesso Solar, Percepção Humana, Urbanismo.

\begin{abstract}
The solar access provision is the elementary requirement to provide passively illumination and heating. However, when urban regulations are insufficient or inefficient in prescribing minimal daily values to solar access levels, the geometry of buildings might cause solar blocking, shading, humidity and cold. It may worsen by unawareness or disregard of professionals about the perception and preferences related to solar access of dweller's buildings, which can result in situations where environment comfort can be regulated by technical recommendations, but not to human requirements. This research aims to produce a validate tool to survey quantitative data regarding the solar access perception of dwellers of 138 housing units located in Curitiba, the coldest capital of Brazil. It's situated at Bioclimatic Zone 1, where the utilization of lighting and heating potential is critically necessary. As reference, an existing questionnaire in English, created to research preferences related to time, quantity, place and purpose of solar access to dwellers of housing units in Hong Kong was used. The original questionnaire was translated and adapted by back translation; hereafter, it was validated by five specialists in natural daylight. After the incorporation of their considerations, a pilot test was made between $3^{\text {rd }}$ and $6^{\text {th }}$ March 2014, with the submission of questionnaire to a probabilistic sample ( $n=33,24 \%$ of population). The collected data had its reliability score calculated and attested by Cronbach's alpha index, $(\alpha=0,838)$. It indicates the questionnaire is appropriated to its aim, and it contributes in researches about human perception related to solar access.
\end{abstract}




\section{INTRODUÇÃO}

Dentre as variáveis envolvidas no processo de condicionamento passivo de uma edificação, está o acesso solar. Sua provisão adequada pode propiciar níveis adequados de aquecimento e iluminação, favorecendo o desenvolvimento das atividades de seus usuários (BOUBEKRI, 2008, pp. 1-2; LAU; NG; HE, 2011, p. 1787; LITTLEFAIR, 2001, p. 180; PHILLIPS, 2004, p. 18). A geometria de um edifício pode afetar o acesso solar dos edifícios adjacentes; para que não haja o bloqueio ao sol ou a criação de sombras indesejadas, é necessário que fatores como latitude e orientação solar sejam levados em conta na concepção de planos urbanísticos. É necessária também a determinação de limites claros para relações de altura e comprimento, e a especificação de recuos mínimos entre as construções, que devem ser respeitados na criação de projetos arquitetônicos e urbanísticos (ESCH, VAN; LOOMAN; BRUIN-HORDIJK, DE, 2012, pp. 190-192; CASTRO PÉREZ; FÁVERO, 2009, p. 2; CASTRO PÉREZ, 2013, p. 59).

Quando a variável acesso solar é negligenciada na fase de projeto, pode-se ter como resultado ambientes que apresentam umidade excessiva, pouca iluminação e frio intenso em determinadas estações do ano, dependendo da latitude em que se encontram (FROTA; SCHIFFER, 2001, pp. 53-56; MARINS; ROMÉRO, 2012). Este conjunto de fatores pode ocasionar efeitos negativos na saúde humana, como desconforto térmico e visual (PRADO, 2006, p. 12; SEONG et al., 2006, p. 723). Além destes efeitos tradicionalmente relacionados ao acesso solar e à saúde dos usuários de edificações, na última década tem-se observado a ampliação da discussão, com a inclusão dos possíveis efeitos da falta de acesso solar em processos biológicos mais complexos, como o metabolismo, regulação da produção hormonal e a sincronização do ciclo circadiano (BOUBEKRI, 2008, p. 53), e em desordens emocionais, como mudanças de humor, depressão, letargia, entre outros (ibid., 2008, pp. 56-60).

Além destes fatores, para a definição de valores de acesso solar adequados aos ocupantes de um edifício, também é necessário considerar que a preferência dos indivíduos perante a luz solar quanto ao seu tempo de exposição, quantidade, local e propósito pode variar, de acordo com a latitude em que se encontram. Ocupantes de edifícios em regiões quentes preferem controlar, ou mesmo excluir a luz solar, de forma a evitar o super aquecimento. Por outro lado, ocupantes de prédios localizados em lugares frios, localizados a altas latitudes, tendem a considerar a possibilidade de acesso à luz solar não só como positiva, mas necessária (LITTLEFAIR, 2001, p.180). Por fim, a demanda por luz solar pode diferir também de acordo com o tipo de edifício, das atividades nele desenvolvidas, e do grau de adensamento em seu entorno (LAU; NG; HE, 2011, p. 1789).

Desta forma, a definição de recomendações efetivas relacionadas à luz solar no interior de edificações deve ser resultado da integração de fatores relacionados à disponibilidade de luz solar (orientação, latitude e condições locais, entre outros) com a avaliação criteriosa dos fatores subjetivos relacionados às preferências de seus usuários (MESA; CORICA; PATTINI, 2011, p. 2414), além da componente biológica e psicológica (MARTAU, 2009, p. 128). Caso contrário, estas definições poderão estar em consonância a recomendações técnicas, sem, no entanto, atender a demandas humanas.

Embora a importância de se conhecer as preferências dos indivíduos relacionadas ao acesso solar se evidencie sob este contexto, constatou-se após a revisão bibliográfica, a inexistência de uma ferramenta validada para esta finalidade na língua portuguesa. Assim, este estudo teve o objetivo de desenvolver, validar e determinar o índice de confiabilidade de um instrumento de coleta de dados, com a finalidade de levantar as preferências de moradores de edificações relacionadas ao acesso solar em habitações localizadas em Curitiba, a capital mais fria do país. Nesta localidade, a importância do acesso solar é evidenciada pelas estratégias bioclimáticas 
sugeridas (aquecimento solar e exploração da inércia térmica dos materiais), sendo que o condicionamento térmico passivo é insuficiente durante o período mais frio do ano (LAMBERTS et al., 1997, p.120).

\section{MÉTODO}

Quanto à metodologia adotada, a pesquisa é classificada como aplicada, por sua natureza; quantitativa, quanto à abordagem do problema; exploratória, pelos objetivos; e experimental, quanto aos procedimentos. O roteiro metodológico adotado no processo de desenvolvimento e adaptação, validação e avaliação do índice de confiabilidade da ferramenta de coleta de dados envolveu a realização de cinco etapas: (1) Execução do processo de back translation; (2) Validação do questionário; (3) Execução do teste piloto com o questionário; (4) Aplicação de teste correlacional nos dados coletados; (5) Formatação da versão final do questionário após teste piloto.

\subsection{Execução do processo de back translation}

A estrutura das questões do instrumento baseou-se em trabalho de Lau, $\mathrm{Ng}$ e He (2011), que realizaram o levantamento das preferências relacionadas ao acesso solar em moradores de habitações de Hong Kong, cidade asiática de alta densidade, de clima subtropical. Esta percepção foi levantada por questionário composto por nove perguntas fechadas. Este, criado para ser aplicado em indivíduos chineses, foi publicado em artigo científico em inglês. Assim, para que o instrumento de coleta de dados pudesse ser utilizado no Brasil, foi necessária a realização de sua tradução, adaptação cultural e validação, bem como a avaliação de seu índice de confiabilidade.

As etapas básicas do processo de back translation envolvem: (1) tradução do texto original (Source Language Text One, SLT1) para a segunda língua, (Target Language Text, TLT); (2) tradução do TLT de volta para a linguagem do SLT1 por um segundo tradutor, desconhecido do tradutor de SLT1, que não sabe que o texto que ele traduzirá é um SLT1, (resultando no back translation, SLT2); (3) comparação de SLT1 a SLT2; e (4) com base nas diferenças e similaridades entre SLT1 e SLT2, realizar uma análise acerca da equivalência entre TLT e SLT1 (HARKNESS; SCHOUA-GLUSBERG, 1998). Assim, foi inicialmente realizada a tradução do conteúdo original das questões do questionário (SLT1) por dois pesquisadores bilíngues (português e inglês) ligados à área de iluminação natural, de forma independente, com o intuito de preservar o significado de termos específicos da área. As duas versões do questionário traduzido foram então comparadas e conciliadas em conjunto pelos mesmos indivíduos, produzindo a tradução final (TLT). Esta foi traduzida para o inglês por tradutor independente (SLT2), com vivência de cinco anos em país de língua inglesa, sem conhecimento do processo anterior de tradução que o questionário havia sofrido, e da finalidade da tradução que realizou. Na sequência, as duas versões (SLT1 e SLT2) tiveram o grau de similaridade avaliado e constatado, quando não foram identificadas divergências que prejudicassem o sentido das questões. Sendo assim, após os ajustes finais, a versão final da tradução e adaptação do instrumento de coleta de dados, composto por nove perguntas fechadas, foi obtida.

\subsection{Validação do questionário}

Após a conclusão do back translation, passou-se à etapa de validação do conteúdo do questionário. Esta consiste em examinar a precisão de uma determinada predição ou inferência feita a partir dos escores de um teste. Ou seja, a validação visa verificar se o instrumento efetivamente é eficaz na mensuração do que se propõe a medir. A validação de conteúdo não é determinada estatisticamente, ou seja, não pode ser expressa por um coeficiente de correlação, mas resulta do julgamento feito por diferentes examinadores 
especialistas, que analisam a representatividade dos itens em relação às áreas de conteúdo e à relevância dos objetivos a medir (RAYMUNDO, 2009, p.87).

Os critérios utilizados para a seleção dos especialistas responsáveis por avaliar e validar o conteúdo do instrumento de pesquisa foram os seguintes: professores universitários doutores, ligados à área de arquitetura e engenharia, brasileiros, com experiência acadêmica mínima de cinco anos em temas de pesquisa relacionados à iluminação natural. Foram convidados cinco profissionais com este perfil, que realizaram a avaliação para validação do conteúdo do questionário em formulário específico disponibilizado de forma online na plataforma de pesquisas Qualtrics ${ }^{\circledR}$. Esta ferramenta permitiu criar o questionário, distribuí-lo aos avaliadores e coletar os dados resultantes do processo de validação, bem como acompanhar as respostas, gerar relatórios e exportar os dados para serem processados por outros aplicativos.

Os itens clareza e coerência de cada uma das nove questões foram assim avaliados como "muito inapropriado", "inapropriado", "apropriado" e "muito apropriado" em uma escala Likert. Foi também disponibilizado um campo aberto para o registro de sugestões de correção, adaptação e melhoria de cada uma das questões, que foram integralmente incorporadas questionário. As alterações sugeridas pelos avaliadores concentraram-se especialmente na necessidade de substituição de termos técnicos ou não usuais por outros mais comuns.

\subsection{Execução do teste piloto com o questionário}

Figura 1 - Habitações pertencentes à amostra (vermelho)

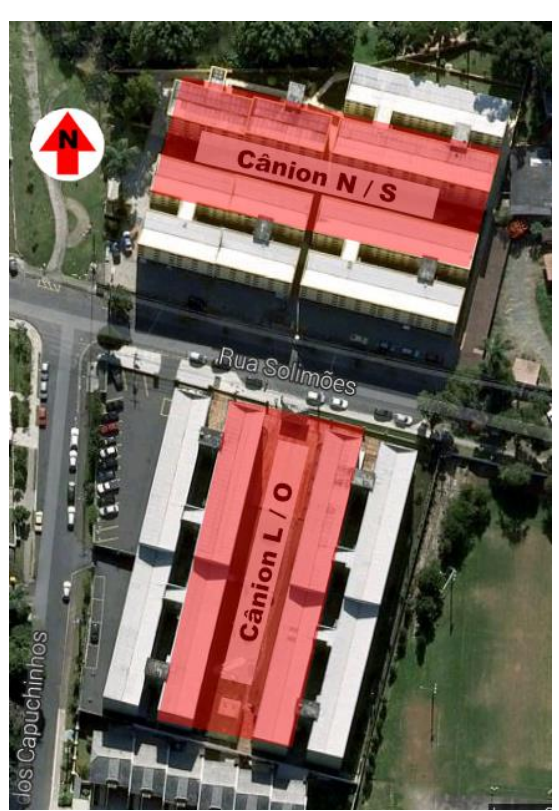

Fonte: autoria própria
O teste piloto foi realizado com $n=33$. A amostra representa $24 \%$ da população selecionada, composta por moradores de 138 apartamentos (todos com plantas idênticas $-60 \mathrm{~m}^{2}$ ) de dois conjuntos habitacionais, localizados na cidade de Curitiba. O primeiro conjunto habitacional, denominado Norte/Sul, é composto por 8 blocos, com quantidade de andares variável, e um total de 118 apartamentos. Os blocos estão dispostos em duplas, que por sua vez são dispostas de forma a formar um cânion urbano que contém fachadas orientadas a aproximadamente Norte e Sul.

O segundo conjunto habitacional, denominado de Leste/Oeste, possui a mesma distribuição de blocos e andares (variável), com um total de 144 apartamentos; neste caso, a disposição dos blocos resulta na formação de um cânion urbano, com fachadas orientadas aproximadamente a Leste e a Oeste. As unidades habitacionais selecionadas para formarem a população avaliada (138 unidades) são aquelas cujas aberturas dos quartos estão voltadas para os dois cânions, resultando em orientações a Norte e Sul, e Leste e Oeste (Figura 1). Mediante procedimentos estatísticos, foram realizadas ordenações probabilísticas separadamente para o total de unidades habitacionais voltadas para cada uma das orientações (Norte, Sul, Leste e Oeste), num total de 138. Os questionários foram então aplicados aos moradores das unidades voltadas para cada uma das orientações, respeitando-se a sequência de ordenação estabelecida, entre os dias 3 e 6 de março de 2014. Quando não havia ninguém na residência, ou quando o morador declinava ao convite de participar da pesquisa, passava-se para a próxima moradia determinada pela lista. $\mathrm{O}$ indivíduo que atendia o pesquisador era o convidado a participar da pesquisa. Esse procedimento foi realizado até que houvesse pelo menos oito questionários respondidos para cada uma das quatro orientações avaliadas. 
O instrumento de coleta de dados foi concebido para ser respondido online via plataforma Qualtrics®; um tablet foi disponibilizado para o preenchimento do questionário. Entretanto, notou-se que nem todos os respondentes possuíam instrução para seu manuseio. Isso somado ao fato de que a conexão com a internet apresentou constantes interrupções, o que poderia causar a perda de dados, levou à substituição da versão eletrônica do questionário por sua versão impressa.

A aplicação do questionário foi feita pelo pesquisador, atento à eventuais dificuldades para a compreensão das questões. Houve apenas uma ocorrência neste sentido, que foi corrigida na versão final do instrumento (descrito no item 2.5 desta seção). O questionário foi composto por um total de 22 perguntas, divididas em duas partes. A primeira parte continha campos para identificação e data, além de 13 perguntas sobre o perfil do respondente (sexo, idade, estado civil, grau de formação); continha também questões relacionadas ao tempo de residência na moradia, quantidade de moradores e horas de permanência no interior da moradia. Já a segunda parte do questionário possuía as nove perguntas relacionadas à percepção do acesso solar, cuja validação foi realizada. Seu enunciado final pode ser visualizado no Quadro 3.

\subsection{Aplicação de teste correlacional nos dados coletados}

A confiabilidade (reliability) dos dados obtidos pelo questionário foi verificada pelo método de Cronbach. Para Sampieri et al. (2006), confiabilidade é o grau de consistência e coerência dos resultados originados de um instrumento de coleta de dados. Segundo Hair et al. (2005), confiabilidade pode ser entendida como a extensão em que uma variável, ou um conjunto de variáveis, é coerente com o objeto de estudo mensurado. Isto significa que se as medidas forem confiáveis, uma nova aplicação do instrumento deve apresentar consistência com seus valores obtidos anteriormente. Maroco e Garcia-Marques (2006, p. 66) afirmam que qualquer menção à confiabilidade de dados suscita referência ao índice alfa de Cronbach. Este foi utilizado para comprovar a consistência dos conjuntos de variáveis referentes ao acesso solar. Para isso, foram incluídos na definição do índice, o resultado das perguntas: (1) entrada de luz solar nos ambientes do apartamento; (2) preferência de período para entrada da luz solar; (3) suficiência da luz solar; (4) importância da luz solar; (5) preferência de quantidade de entrada da luz solar; (6) quantidade de horas de luz solar; (7) aspectos positivos da luz solar e; (9) percepção sobre os aspectos ambientais no apartamento de maneira geral. A pergunta (8), sobre os aspectos negativos da luz solar foi excluída da análise, pois não houve um número suficiente de opções escolhidas pelos respondentes que possibilitasse o cálculo do seu índice de confiabilidade. Maroco e Garcia-Marques (2006) apresentam a fórmula para o alfa de Cronbach conforme indicado na Eq. 1.

$$
\alpha=\frac{k}{(k-1)} \times\left[1-\frac{\sum_{j=1}^{k} S_{j}^{2}}{S_{T}^{2}}\right]
$$

onde, $k=$ número de itens (perguntas) do instrumento,

$$
\begin{aligned}
& S_{j}^{2}=\frac{1}{n-1} \sum_{i=1}^{n}\left(X_{i j}-\bar{X}_{j}\right)^{2} \quad \text { é variância do item } j(j=1, \ldots, k), \\
& S_{T}^{2}=\text { variância dos totais, } \\
& \alpha=\text { alfa de Cronbach. }
\end{aligned}
$$

$\mathrm{O}$ alfa de Cronbach pode variar entre 0 e 1,0; as medidas mais altas indicam maior confiabilidade dos dados. Os valores entre 0,60 e 0,70 representam o limite inferior de aceitabilidade do índice (HAIR et al., 2005). Maroco e Garcia-Marques (2006). 
salientam que, de maneira geral, uma confiabilidade apropriada deve apresentar um valor de pelo menos 0,70 para o alfa de Cronbach.

Para as perguntas 1 e 2 do questionário, referentes à incidência de luz solar e à preferência em relação à incidência de luz solar no interior dos apartamentos respectivamente, foi aplicado um procedimento de agrupamento, com o objetivo de reduzir o resultado para apenas uma variável por pergunta, de forma a viabilizar a aplicação do teste alfa de Cronbach. Este agrupamento obedeceu à regra de categorização apresentada na Tabela 1.

Tabela 1 - Categorização de variáveis

\begin{tabular}{lcc}
\hline Resposta & Pontos & $\begin{array}{c}\text { Valor final da } \\
\text { variável }\end{array}$ \\
\hline Nunca & 0 & 0 \\
Manhã & 1 & Somatório dos pontos \\
Meio-dia & 1 & -1 \\
Tarde & 1 & \\
Indiferente & -1 &
\end{tabular}

Obteve-se assim apenas um valor para cada variável, de maneira que o valor 0 indica que nunca há incidência de luz no ambiente; 1 indica que em um período do dia há luz solar no ambiente; e -1, que a incidência de luz solar naquele ambiente é indiferente para o respondente.

\subsection{Formatação da versão final validada do questionário após teste piloto}

O acompanhamento realizado durante a fase de aplicação das nove questões possibilitou a avaliação do grau de entendimento do que estava sendo perguntado. Apenas uma (pergunta 9, sobre a percepção acerca dos aspectos ambientais gerais) causou dúvidas nos respondentes, e necessitou de ajustes nas opções de resposta; as opções "insuficientemente", "suficientemente" e "excessivamente" foram substituídas consecutivamente por "pouco", "suficientemente" e "muito". Para as demais questões, o formato obtido após a etapa de validação do questionário mostrou-se adequado.

\section{RESULTADOS}

\section{6 Índice de Confiabilidade}

O alfa de Cronbach calculado para determinação da confiabilidade do instrumento de coleta de dados foi igual a 0,838; assim, atestou-se a consistência e a coerência das questões. As questões que constituem o instrumento de coleta de dados obtido se mostraram então adequadas a medir o que se propõe, exceto pela pergunta 8 , que levanta as razões pelas quais não se aprecia a luz solar dentro da moradia. Como não houve quantidade suficiente de respostas (os respondentes possuíam a opção de selecionar todas, algumas ou nenhuma das opções oferecidas), não foi possível determinar estatisticamente o índice de confiabilidade desta questão.

\subsection{Formato final do instrumento de coleta de dados}

Durante as etapas do processo de desenvolvimento do questionário, suas nove questões passaram por alterações (tradução, adaptação cultural, substituição de palavras e expressões) de forma a facilitar sua compreensão. Ao final das etapas, obteve-se a formatação final do instrumento de coleta de dados, apresentada no Quadro 1.

\section{Quadro 1 - Formato final do instrumento de coleta de dados}

\begin{tabular}{|c|l|l|}
\hline $\mathbf{N}^{\mathbf{0}}$ & \multicolumn{1}{|c|}{ Enunciado da Questão } & \multicolumn{1}{|c|}{ Opções de resposta } \\
\hline 1 & $\begin{array}{l}\text { Em que períodos do dia você tem entrada de luz solar } \\
\text { nos seguintes ambientes de seu apartamento? (Se } \\
\text { necessário, assinale mais de uma opção para cada } \\
\text { ambiente). }(*)\end{array}$ & $\begin{array}{l}\text { (1) Nunca (2) Manhã (3) Meio-dia } \\
\text { (4) Tarde }\end{array}$ \\
\hline
\end{tabular}




\begin{tabular}{|c|c|c|}
\hline 2 & $\begin{array}{l}\text { Em que períodos do dia você preferiria ter luz solar nos } \\
\text { ambientes de seu apartamento? (Se necessário, assinale } \\
\text { mais de uma opção para cada ambiente). }(*)\end{array}$ & $\begin{array}{l}\text { (1) Nunca (2) Manhã (3) Meio-dia } \\
\text { (4) Tarde (5) Indiferente }\end{array}$ \\
\hline 3 & $\begin{array}{l}\text { Você acha que a luz solar que entra no seu apartamento } \\
\text { é: (Assinale uma opção para cada ambiente). }(*)\end{array}$ & (1) Excessiva (2) Suficiente (3) Pouca \\
\hline 4 & $\begin{array}{l}\text { Para você, o grau de importância da luz solar nos } \\
\text { ambientes de seu apartamento é: (Assinale uma opção } \\
\text { para cada ambiente). }(*)\end{array}$ & $\begin{array}{l}\text { (1) Muito baixo (2) Baixo } \\
\text { (3) Indiferente (4) Alto (5) Muito alto }\end{array}$ \\
\hline 5 & $\begin{array}{l}\text { Em relação à luz solar que entra em seu apartamento, } \\
\text { você preferiria ter: (Assinale uma opção para cada } \\
\text { ambiente). }\end{array}$ & $\begin{array}{l}\text { (1) Nenhuma luz solar (2) Menos que } \\
\text { atualmente (3) Manter o acesso atual } \\
\text { (4) Mais que atualmente (5) O máximo } \\
\text { possível }\end{array}$ \\
\hline 6 & $\begin{array}{l}\text { Quantas horas com luz solar você preferiria ter } \\
\text { diariamente em seu apartamento? : (Assinale uma opção } \\
\text { para cada ambiente). }(*)\end{array}$ & $\begin{array}{l}\text { (1) Nenhuma luz solar } \\
\text { (2) De } 1 \text { a } 2 \text { horas (3) De } 2 \text { a } 3 \text { horas } \\
\text { (4) De } 3 \text { a } 4 \text { horas (5) Mais de } 4 \text { horas }\end{array}$ \\
\hline 7 & $\begin{array}{l}\text { Quais são os principais aspectos positivos da luz solar? } \\
\text { (Selecione quantas opções achar necessário). }\end{array}$ & $\begin{array}{l}\text { (1) Melhoria da saúde (2) Melhoria do } \\
\text { humor (3) Melhoria da iluminação } \\
\text { (4) Aquecimento (5) Secagem de roupas } \\
\text { (6) Higienização (7) Desumidificação } \\
\text { do ambiente (8) Crescimento das plantas }\end{array}$ \\
\hline 8 & $\begin{array}{l}\text { Quais são os principais aspectos negativos da luz solar? } \\
\text { (Selecione quantas opções achar necessário). }\end{array}$ & $\begin{array}{l}\text { (1) Excesso de calor (2) Vista ofuscada } \\
\text { (3) Risco de câncer de pele } \\
\text { (4) Deterioração de mantimentos na } \\
\text { cozinha (5) Ressecamento de objetos } \\
\text { (6) Desbotamento de objetos }\end{array}$ \\
\hline 9 & $\begin{array}{l}\text { De forma geral, qual é a sua percepção sobre os } \\
\text { seguintes aspectos de seu apartamento? } \\
\text { (Assinale uma opção para cada pergunta). }\end{array}$ & (1) Pouco (2) Suficientemente (3) Muito \\
\hline
\end{tabular}

(*) A questão avalia individualmente aos ambientes estar, quarto e cozinha.

Fonte: autoria própria

\subsection{Resultados do teste piloto relativos à caracterização do perfil da amostra e suas preferências dos indivíduos relacionadas ao acesso solar em suas moradias}

Houve a predominância de indivíduos do sexo feminino $(n=24,73 \%)$, adultos (19 a 59 anos, $n=23,70 \%)$, com ensino médio completo ( $n=12,36 \%$ do total). Verificou-se que $\mathrm{n}=14$ (42\% do total) residem no mesmo local entre 1 e 5 anos, a mesma quantidade de indivíduos que residem no mesmo local há mais de 10 anos. As moradias são, predominantemente, habitadas por 2 indivíduos ( $n=16,48 \%$ do total). Quanto às questões sobre acesso solar, a Questão 1, que verifica a incidência de luz solar no apartamento, ressaltou o predomínio da entrada de luz na manhã e à tarde (Gráfico 1).

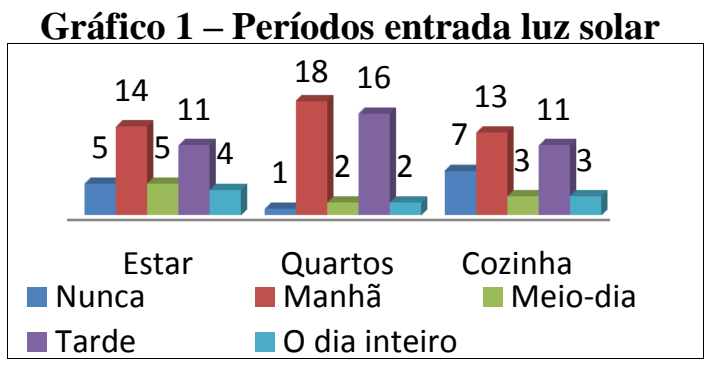

Fonte: autoria própria
Gráfico 2 -Preferência entrada luz solar

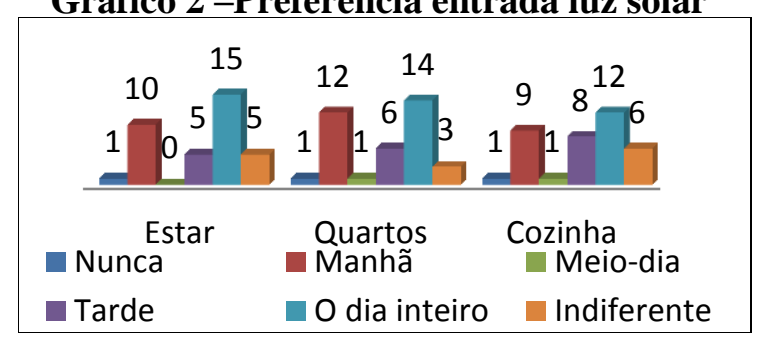

Fonte: autoria própria

Houve maior ocorrência de incidência para os quartos do que para a sala de estar e cozinha. Além disso, $15 \%$ dos respondentes não possuem luz solar na sala de estar em nenhum momento do dia, e $21 \%$ nunca recebem luz solar na cozinha. Nos quartos, este fato ocorreu apenas uma vez (3\% da amostra). 
A Questão 4 era sobre o grau de importância da luz solar para os ambientes (Gráfico 4). A importância da luz solar foi considerada alta pela maioria em todos. O maior percentual (54\%) foi para a sala de estar, seguida pelos quartos $(45 \%)$ e pela cozinha (42\%). Ninguém declarou que a importância da luz solar é muito baixa. Embora a opção que indicava uma importância "muito alta" para a luz solar não tenha sido maioria em nenhum dos ambientes, o somatório de seus valores aos da opção "alto" evidencia a importância do acesso solar em todos os ambientes pela maioria dos moradores. Isto indica que $79 \%$ julga a luz solar altamente importante na sala de estar e nos quartos, e 73\% pensam da mesma maneira para a cozinha.

Gráfico 3 - Luz solar que entra é:

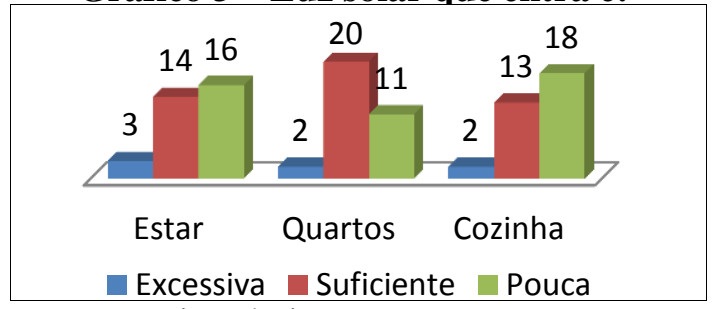

Fonte: autoria própria
Gráfico 4 - Importância da luz solar

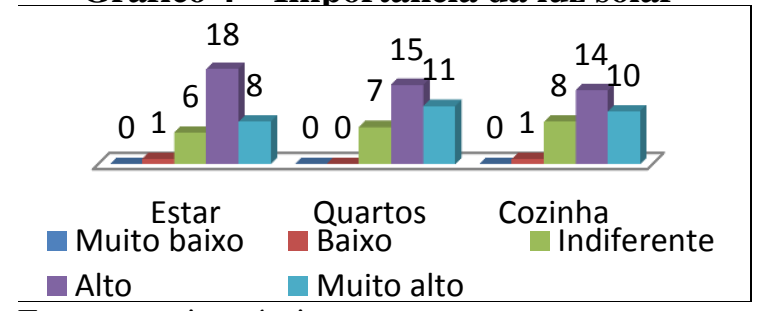

Fonte: autoria própria

A Questão 5 era sobre a preferência relacionada à preferência por haver mais ou menos luz solar na moradia (Gráfico 5). Em todos os ambientes, a opção mais escolhida foi manter o padrão atual, e o maior percentual encontrado foi para os quartos, (58\%), seguido pela sala de estar e cozinha, com $42 \%$ cada. Entretanto, se somadas as duas opções que possibilitam maior entrada de luz solar nos ambientes, "Mais que atualmente" e "O máximo possível", a proporção de moradores que gostariam de aumentar o acesso é maior na sala de estar e na cozinha, com 55\% em cada. Para os quartos este percentual é de 39\%, ficando abaixo da ocorrência de moradores que desejam manter o padrão atual de acesso solar. Apenas 1 morador gostaria de diminuir a quantidade de luz solar em sua moradia.

Gráfico 5 - Preferência em relação à luz

$$
\begin{gathered}
\text { Estar Quartos Cozinha } \\
\quad \begin{array}{c}
\text { Nenhuma luz solar } \\
\text { Menos que atualmente } \\
\text { Manter o padrão atual }
\end{array}
\end{gathered}
$$

Fonte: autoria própria
Gráfico 6 - Preferência qtde. horas luz

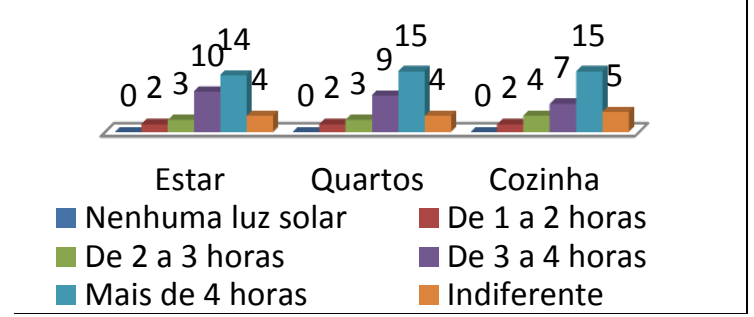

Fonte: autoria própria

A Questão 6 era sobre a preferência em relação à quantidade de horas com acesso solar em cada ambiente dos apartamentos (Gráfico 6). Os resultados obtidos indicam que quase metade dos respondentes (45\% para quartos e cozinha, $42 \%$ para sala de estar) gostaria de mais de quatro horas de luz solar diariamente em suas moradias, e corrobora os resultados da pergunta sobre os períodos de acesso solar, onde a maioria dos respondentes afirmou que gostaria de luz solar durante todo o dia.

As Questões 7 e 8 relacionavam-se aos aspectos positivos e negativos da luz solar (Gráficos 7 e 8). O fator positivo mais citado foi a melhoria da saúde com 91\%, ou seja, somente três pesquisados não julgaram este item relevante. Em segundo lugar, vieram as opções melhoria da iluminação e da desumidificação do ambiente, com 28 respondentes cada (82\%). Todas as demais opções foram marcadas por mais de $70 \%$ dos entrevistados, com exceção ao item referente à influência positiva da luz solar no crescimento de plantas $(n=17,52 \%)$, que mesmo tendo o pior desempenho, foi considerado importante por mais da metade da amostra. 
Gráfico 7 - Aspectos positivos luz solar

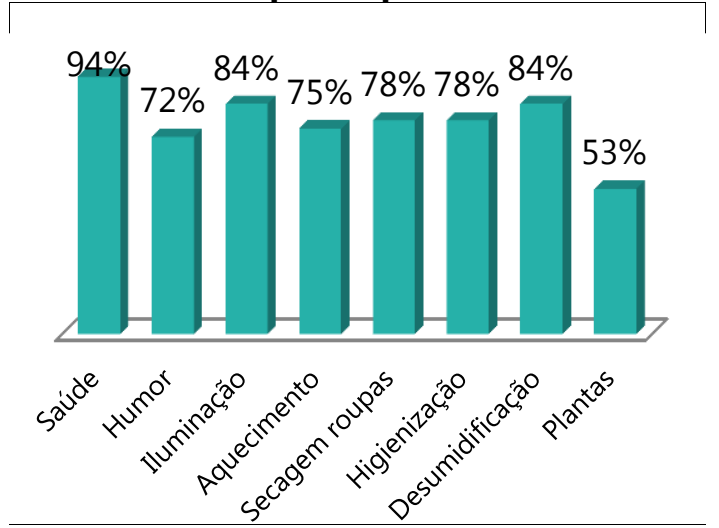

Fonte: autoria própria
Gráfico 8 - Aspectos negativos luz solar

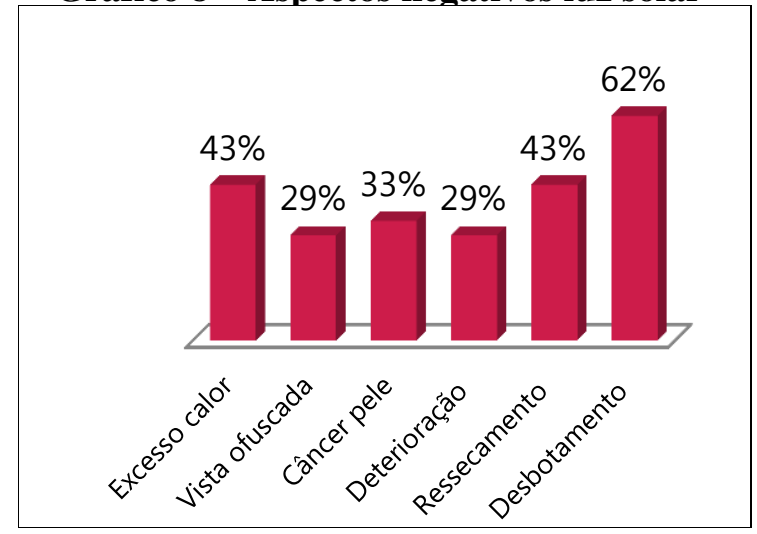

Fonte: autoria própria

Quanto aos aspectos negativos, nenhum foi assinalado por mais de $50 \%$ dos respondentes. A opção mais assinalada foi desbotamento de objetos $(n=13)$, seguido por excesso de calor e ressecamento de objetos $(n=9$, igual a $27 \%)$. Os respondentes apontaram poucos aspectos negativos relacionados à luz solar, o que impossibilitou inclusive a avaliação de sua confiabilidade pelo alfa de Cronbach.

A Questão 9 abordava diversos aspectos das moradias e solicitava que os respondentes escolhessem entre as opções "Pouco", "Adequado" e "Excessivo" (Gráfico 9).

\section{Gráfico 9 - Percepcão geral sobre a moradia}

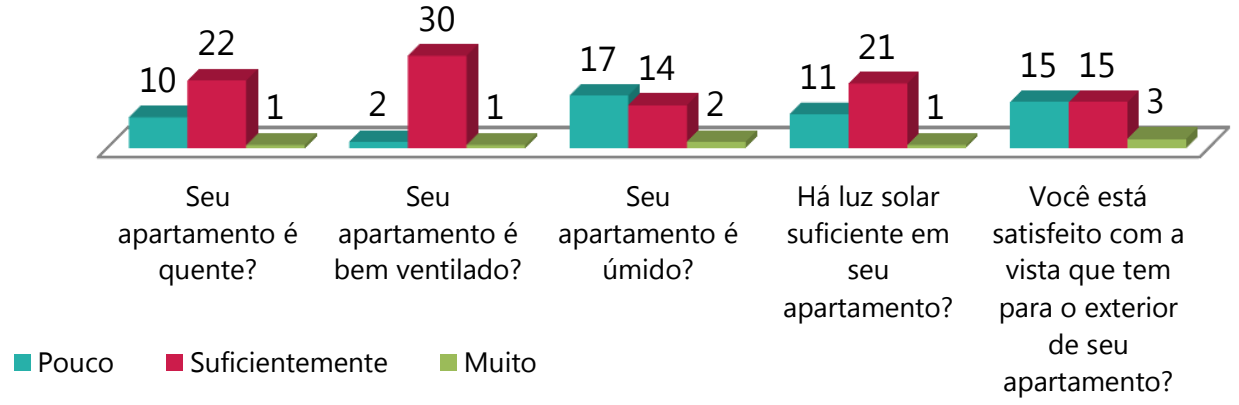

Fonte: autoria própria

Dentre os itens abordados, a ventilação apresentou o melhor desempenho e foi julgada adequada por $90 \%$ dos respondentes. Em segundo lugar, a temperatura também foi julgada adequada pela maioria $(n=22,67 \%)$. A satisfação com a vista para o exterior apresentou valores iguais para os pouco e adequadamente satisfeitos ( $\mathrm{n}=15$ para cada).

\section{CONSIDERAÇÕES FINAIS}

Os procedimentos adotados para o desenvolvimento do instrumento de coleta de dados (back translation e validação de conteúdo) mostraram-se adequados. Isto pode ser afirmado pelo fato de o questionário com nove perguntas resultante foi utilizado no teste piloto $(n=33)$ sem que fossem registradas ocorrências de falta de entendimento quanto ao que estava sendo perguntado. Somente a Questão 9 (sobre a percepção relacionada aos aspectos ambientais da moradia) registrou dúvidas quanto às opções de resposta, o que pôde ser esclarecido durante a aplicação do questionário, e que recebeu o devido ajuste posteriormente, quando se produziu a versão final questionário. Os dados obtidos com o teste piloto tiveram sua confiabilidade aferida por meio do cálculo do alfa de Cronbach, cujo resultado $(\alpha=0,838)$ indica um índice adequado de consistência e coerência. Assim, o instrumento é válido, e poderá contribuir em futuras pesquisas correlatas. Os dados descritivos estatísticos obtidos com o teste piloto 
evidenciaram que a maioria dos indivíduos da amostra possui preferência por ambientes ensolarados, e que as características positivas relacionadas ao acesso solar são mais relatadas quando comparadas com as características negativas, o que impossibilitou inclusive que a questão que tratava destas fosse incluído no cálculo de confiabilidade. As próximas etapas da pesquisa incluem levantamento in loco e simulações das condições de acesso solar nas moradias dos respondentes, a fim de se avaliar se a percepção destes relacionada ao acesso solar é compatível com as condições reais físicas encontradas no ambiente (orientação dos prédios, posicionamento das aberturas).

\section{REFERENCIAS}

BOUBEKRI, M. Daylighting, architecture and health. Routledge, 2008.

CASTRO PEREZ, D. R. Diretrizes solares para o planejamento urbano: o envelope solar como critério para adensamento e verticalização. Campinas, Faculdade de Engenharia Civil, Arquitetura e Urbanismo, Universidade Estadual de Campinas, 2013, 255 p. Tese de Doutorado.

CASTRO PEREZ, D. R.; FAVERO, E. . O envelope solar como instrumento de regulamentação de acesso ao sol no espaço urbano e nas edificações: o caso de Campinas/SP, Brasil. In: XIII Seminario de Arquitectura Latinoamericana: Arquitectura y Clima, v. 1. p. 1-3, 2009.

ESCH, M. M. E. VAN; LOOMAN, R. H. J.; BRUIN-HORDIJK, G. J. DE. The effects of urban and building design parameters on solar access to the urban canyon and the potential for direct passive solar heating strategies. Energy and Buildings, v. 47, p. 189-200, 2012.

FROTA, A. B.; SCHIFFER, S. R. Manual de Conforto Térmico. Studio Nobel, 2001.

HARKNESS, J. A.; SCHOUA-GLUSBERG, A. Questionnaires in translation. ZUMA-Nachrichten Spezial, v. 3, n. 1, p. 87-127, 1998.

LAMBERTS, R.; DUTRA, L. e PEREIRA, F. O.R. Eficiência energética na arquitetura. São Paulo: PW Editores, 1997.

LAU, K. L.; NG, E.; HE, Z. J. Residents' preference of solar access in high-density sub-tropical cities. Solar Energy, v. 85, n. 9, p. 1878-1890, 2011.

LITTLEFAIR, P. Daylight, sunlight and solar gain in the urban environment. Solar Energy, v. 70, n. 3, p. 177-185, 2001.

MARINS, K. R. DE C. C.; ROMÉRO, M. DE A. Integration of urban morphology constraints in the development of a methodology for urban energy planning. Ambiente Construído, v. 12, n. 4, p. 117-137, 2012.

MAROCO, J.; GARCIA-MARQUES, T. Qual a fiabilidade do alfa de Cronbach? Questões antigas e soluções modernas. Laboratório de Psicologia, v. 4, n. 1, p. 65-90, 2006.

MARTAU, B. T. A luz além da visão: iluminação e sua relação com a saúde e bem-estar de funcionárias de lojas de rua e shopping centers em Porto Alegre. Campinas, 2009. 504 f. Tese (Doutorado em Engenharia Civil) Faculdade de Engenharia Civil, Arquitetura e Urbanismo. Universidade Estadual de Campinas, 2009.

MESA, N. A.; CORICA, L.; PATTINI, A. Evaluation of the potential of natural light to illuminate buildings in dense urban environment. A study in Mendoza, Argentina. Renewable Energy, v. 36, n. 9, p. 2414-2423, 2011.

PHILLIPS, D. Daylighting: natural light in architecture. Routledge, 2004.

PRADO, A. L. Em busca da pertinência para uma arquitetura tropical. MDC Revista de Arquitetura e Urbanismo. Belo Horizonte, Officina 3 Consultores Associados, n.1, 2 e 3, p. 10-13, 2006. RAYMUNDO, V. P. Construção e validação de instrumentos: um desafio para a psicolinguística. Letras de Hoje-Estudos e debates em linguística, literatura e língua portuguesa, v. 44, n. 3, 2009.

SAMPIERI, R. H. et al. Metodologia de pesquisa. 5. ed. Porto Alegre: Penso, 2006. 624 p. SEONG, Y.-B. et al. Solar rights analysis system for apartment buildings. Solar energy, v. 80, n. 6, p. 723-741, 2006. 